\author{
KEIO UNIVERSITY \\ KEIO/KYOTO MARKET QUALITY RESEARCH PROJECT \\ (Global Center of Excellence Project)
}

KEIO/KYOTO GLOBAL COE DISCUSSION PAPER SERIES

DP2008-026

\author{
Unemployment Risk and the Timing of Homeownership \\ in Japan
}

\author{
Yoko Moriizumi* \\ Michio Naoi**
}

\begin{abstract}
The effect of unemployment risk on the timing of homeownership is examined through the use of a retrospective panel of Japanese households. We obtain the following results by applying the split population duration (SPD) model: (1) unemployment risk, as proxied by the probability of unemployment, has a significantly negative effect on homeownership and delays its timing, (2) the effect of unemployment risk is overestimated in previous studies, which assume that all households will eventually become homeowners, and (3) household characteristics as well as the conditions of housing and labour markets at the early stages of a household's life cycle play an important role in the determination of its housing purchase. Finally, our simulation results indicate that an initial one-year unemployment spell will have a fairly large impact of 1.6-year delay in the timing of a subsequent home purchase.

*Yoko Moriizumi

Faculty of Economics, Kanagawa University

**Michio Naoi

Faculty of Business and Commerce, Keio University
\end{abstract}

KEIO/KYOTO MARKET QUALITY RESEARCH PROJECT

(Global Center of Excellence Program)

Graduate School of Economics and Graduate School of Business and Commerce, Keio University

2-15-45 Mita, Minato-ku, Tokyo 108-8345 Japan

Kyoto Institute of Economics, Kyoto University

Yoshida-honmachi, Sakyo-ku, Kyoto 606-8501 Japan 


\title{
Unemployment Risk and the Timing of Homeownership in Japan
}

\author{
Yoko Moriizumi $^{*}$ and Michio Naoi ${ }^{\dagger}$ \\ Kanagawa University and Keio University
}

\begin{abstract}
The effect of unemployment risk on the timing of homeownership is examined through the use of a retrospective panel of Japanese households. We obtain the following results by applying the split population duration (SPD) model: (1) unemployment risk, as proxied by the probability of unemployment, has a significantly negative effect on homeownership and delays its timing, (2) the effect of unemployment risk is overestimated in previous studies, which assume that all households will eventually become homeowners, and (3) household characteristics as well as the conditions of housing and labour markets at the early stages of a household's life cycle play an important role in the determination of its housing purchase. Finally, our simulation results indicate that an initial one-year unemployment spell will have a fairly large impact of 1.6-year delay in the timing of a subsequent home purchase.
\end{abstract}

JEL classification: R21, J64

Keywords: Timing of Homeownership, Unemployment Risk, SPD Model

\footnotetext{
*Corresponding author. Faculty of Economics, Kanagawa University, 3-27-1 Rokkakubashi, Kanagawa-ku, Yokohama 221-8686, Japan. Email: jyoko@kanagawa-u.ac.jp. Phone: +81-45-481-5661.

${ }^{\dagger}$ Faculty of Business and Commerce, Keio University, 3-1-7 Mita, Minato-ku, Tokyo 108-0073, Japan.Email: naoi@2001.jukuin.keio.ac.jp.
} 


\section{Introduction}

Although there are several sources of the uncertainties that a household faces during its lifetime, income uncertainty might be the most serious one, particularly for a young household that desires to be a homeowner. While the majority of previous studies used income variability as a proxy for income uncertainty, in this paper, we focus on households' unemployment risk - the most extreme form of income reduction that can arise during a household's lifetime.

There are several reasons to expect that unemployment risk will impact homeownership. First, unemployment risk, often measured by an individual's job tenure or past experience with unemployment, is a typical screening device for credit rationing by lenders. According to the Survey of Housing Market Trends (Ministry of Land, Infrastructure and Transport, 2006), almost 20 percent of the households that purchase their own houses are credit rationed due to their unemployment risk. ${ }^{1}$ Moreover, since unemployment forces households to lose not only a stable future income stream but also all of the fringe benefits of employment (such as social and health securities, subsidized housings, and several allowances), its effect on housing tenure transition is much more than a simple reduction in income. Second, as Carroll, Dynan, and Krane (2003) and Lusardi (1998) suggested, unemployment risk has a precautionary effect on a household's wealth accumulation, i.e. the prevailing precautionary saving may 'crowd out' the wealth holdings that are in the form of illiquid assets such as housing.

Owing to these reasons, a household with a higher unemployment risk tends to delay the timing of tenure transition until it obtains a stable job, or it is discouraged from becoming a homeowner. At an aggregate level, a negative relationship between unemployment and homeownership rates might constitute good evidence of the effect of unemployment risk on housing tenure transition. Figure 1 illustrates the recent

\footnotetext{
${ }^{1}$ It should be noted that this survey comprises only those respondents who purchased their homes in 2005. In other words, those who were rationed and did not purchase a home are not included in the survey, thus implying that the share of credit rationed households is almost certainly underestimated.
} 
trends of the homeownership rates and unemployment rates of households whose heads are under 40 years of age. Homeownership in young households has decreased drastically during the past 25 years, while the unemployment rate of workers under 40 years of age has increased during the same period.

(Figure 1 around here.)

There are several theoretical studies that address the relationship between income uncertainty and homeownership. DeSalvo and Eeckhoudt (1982) theoretically predict a negative relationship between housing consumption and the probability of unemployment. Turnbull, Glascock, and Sirmans (1991), using a similar framework, demonstrate that a mean preserving spread of an uncertain income lowers housing consumption; however, when the expected wages are embedded in the compensating differentials for income risk, the relationship becomes ambiguous. Fu (1995) analysed the demand for housing in the presence of liquidity constraints and house price uncertainty. It is shown that an increase in income variability (or a forward tilting in the income path) will have either a positive or a negative effect on homeownership depending on the household's attitude towards risk.

Since theoretical predictions are ambiguous, several empirical analyses have been presented to investigate the relationship between income uncertainty and homeownership. Haurin and Gill (1987) and Haurin (1991) find that the households which are likely to have lower income variability tend to own their houses. Robst, Deitz, and McGoldrick (1999), using several measures of expected income variability, also find a negative relationship between income uncertainty and the likelihood of homeownership. More recently, Diaz-Serrano (2005a, b), using data from three countries, reveals the negative effect of income uncertainty on the probability of homeownership. With regard to unemployment risk, Di Salvo and Ermisch (1997) find that unemployment risk, as indicated by the regional unemployment rate, has a significantly negative effect on the probability of homeownership in Britain. However, their measure of unemployment risk is not individual-level, but rather it is a 
regional-level unemployment rate.

While most of the previous studies used transitory income variation to measure income uncertainty, our measure is a household-specific probability of unemployment obtained from retrospective unemployment history data. Using unemployment risk as a measure of income uncertainty has several advantages over using income variability. First, as noted above, unemployment risk includes a much broader range of income uncertainty. Unemployment forces households to lose not only a stable future income stream but also all of the fringe benefits of employment. Second, as Carroll, Dynan, and Krane (2003), Lusardi (1997, 1998), and Guiso, Jappelli, and Terlizzese (1992) have pointed out, income variability measures might be poor uncertainty proxies because they can contain large controllable elements. For example, a household that desires to be a homeowner might increase its working member's labour supply in order to accumulate sufficient wealth for a downpayment. $^{2}$ In such a case, the household will have more volatile income even if there is no change in the true income uncertainty. ${ }^{3}$ Instead, previous studies suggest that unemployment will be a better candidate for a measure of individual-level income uncertainty. This is because job loss is a major interruption to income and, in many cases, is involuntary, particularly for a married male who is the main earner in a household. ${ }^{4}$ Third, it is often pointed out that measurement error in earnings poses serious problems with respect to empirical findings. Bound and Krueger (1991) report that the error variance represents nearly $25 \%$ of the total variance in earnings. In contrast, the history of unemployment is a relatively accurate measure, resulting in fewer measurement error problems.

The objective of our paper is to examine the effect of unemployment risk on the timing of homeownership by applying a discrete-time hazard model to the most

\footnotetext{
${ }^{2}$ Naoi and Moriizumi (2007) find that a housing purchase plan has a significantly positive effect on the labour supply of a married female, suggesting that married women work for downpayment or due to wealth constraints.

${ }^{3}$ Carroll, Dynan, and Krane (2003) use an example of a tenured college professor who, by choice, teaches or consults every other summer to explain this kind of artificial income variation.

${ }^{4}$ These previous studies all focus on the relationship between unemployment risk and a household's precautionary saving behaviour, which is different from that in our study.
} 
recent household panel data in Japan. We employ a split population duration (SPD) model which allows us to estimate the timing of homeownership as well as determine whether all households eventually purchase homes.

The results are as follows: (1) unemployment risk, proxied by the unemployment probability, has a significantly negative effect on homeownership and delays its timing, (2) the effect of unemployment risk is overestimated in previous studies, which assume that all households will eventually become homeowners, and (3) the conditions of housing and labour markets at the early stages of a household's life cycle play an important role in the determination of a housing purchase.

The remainder of the paper is organized as follows. Section 2 presents the estimation method. A brief description of the data and variables are provided in Section 3. Section 4 provides the empirical results and discusses the relationship between unemployment risk and the timing of homeownership. Finally, Section 5 concludes the paper.

\section{Empirical Model and Estimation Method}

\subsection{Survival Analysis of the Timing of Homeownership}

There are several empirical studies that investigate the timing of homeownership using a survival analysis approach. Guiso and Jappelli (2002) examine the relationship between a private transfer and the timing of tenure transition. Deutsch, Tiwari, and Moriizumi (2006) and Tiwari, Deutsch, and Moriizumi (2007), focusing on wealth accumulation and liquidity constraints, estimate the duration until home purchase. A recent paper by Andrew, Haurin, and Munasib (2006), using British and U.S. longitudinal data, compares the patterns of young adults' transitions to homeownership between these two countries. All these studies apply a standard continuous-time approach such as the semi-parametric Cox proportional hazard model or the parametric Weibull model.

These standard models estimate the hazard of a home purchase, i.e. the probability of a home purchase conditional on waiting until a certain point in time. 
An important assumption of these models is that all households will eventually purchase their own homes, which restricts the ultimate homeownership rate to unity, even though the observed homeownership rate is smaller than unity. By excluding this assumption, the SPD model estimates the likelihood of a household eventually purchasing a home as well as the timing of its home purchase. The SPD model is applied to several topics including smoking behaviour (Forster and Jones 2001; Kidd and Hopkins 2004), criminal recidivism (Schmidt and Witte 1989), and bank failure (DeYoung 2003). However, as far as we know, no previous study has applied the SPD model to the timing of homeownership. It should be noted that the standard model is in fact a special case of the SPD model. ${ }^{5}$ We found that the performance of the SPD model is better than that of the standard duration model.

\subsection{Econometric Model}

Households maximize their lifetime utility within an intertemporal framework. Those households that live in rental housing plan to purchase a house if the lifetime utility of owning a house is greater than that of renting one. Once a household decides to own a house, the timing of its housing purchase is jointly determined depending on the unemployment risk, household wealth, income, mortgage interest rates, and other demographic factors.

Let $e_{i}$ be an unobservable variable expressing the home purchase decision. Denoting $e_{i}=1$ if a household decides to purchase a house at a certain time in the future and $e_{i}=0$ if it decides to continue renting a house, the home purchase decision is modelled as follows:

$$
e_{i}=\mathrm{I}\left(\mathbf{Y}_{i} \delta+\eta_{i}>0\right)
$$

where $\mathrm{I}(\cdot)$ is the indicator function, $\mathbf{Y}_{i}$ is a vector of time invariant covariates, $\delta$ is a parameter vector to be estimated, and $\eta_{i}$ is the error term with a logistic

\footnotetext{
${ }^{5}$ Another point to be noted is that the presence of tied events may cause problems, especially when the unit of time is large. Since the underlying continuous-time process has a zero probability for tied events, the presence of many ties may lead to biased estimates in the case of a continuous-time model (Yamaguchi 1991). A discrete-time model is more appropriate than a continuous-time model and, therefore, is applied in our analysis by using yearly data.
} 
distribution. In the following analysis, $\mathbf{Y}_{i}$ includes household wealth, unemployment risk, and the conditions of labour and housing markets at the beginning of the spell. ${ }^{6}$

For a household that decides to purchase a house $\left(e_{i}=1\right)$, the timing of its home purchase is jointly determined. The timing is measured by the duration until a house is purchased. There are two types of samples in our data-households with complete spells and those with incomplete spells (i.e. right-censored). The households in the former group purchased their homes at a certain time prior to the survey year, while those in the latter group did not. Here, let $c_{i}$ be the observable dummy variable, with $c_{i}=1$ for the complete spell samples and $c_{i}=0$ for the incomplete spell samples.

Suppose that we can observe the occurrence of a home purchase and a set of household characteristics (covariates) at each time $t=1,2, \cdots, T_{i}$ for each $i$. An event occurs at $t=T_{i}$ for the samples with a complete spell, and no event is observed for the incomplete spell samples. The probability of a home purchase conditional on waiting until time $t$ is then denoted by $h(t)=\operatorname{Pr}(T=t \mid T \geq t)$. Given the observed covariates, the log of the odds ratio takes the following form:

$$
\ln (h(t) /(1-h(t)))=\theta_{t} \cdot t+\alpha \operatorname{Pr}\left(U_{i, t+1}=1\right)+\mathbf{X}_{i t} \beta+\mathbf{Z}_{i t} \gamma,
$$

where $t$ is the measure of time (in years) since the completion of the husband's full-time education, and $\theta_{t}, \alpha, \beta$, and $\gamma$ are the parameters to be estimated. $\theta_{t}$ is the piecewise constant slope of the baseline hazard, which varies at every 5-year interval in our specification. $\operatorname{Pr}\left(U_{i, t+1}=1\right)$, which will be explained later, represents the estimated probability of becoming unemployed in the next year (i.e. period $t+1) . \quad \mathbf{X}_{i t}$ is a vector of person-specific variables including both time-varying and fixed characteristics. This includes the marital status, number of children, amount of wealth accumulation, and a set of dummy variables for the individual's birth cohort. $\mathbf{Z}_{i t}$ is a vector of regional and time-series characteristics, which includes relative house prices and mortgage interest rates.

\footnotetext{
${ }^{6}$ For labour and housing market conditions, we use the unemployment rate of male workers, mortgage interest rate, and the relative price of owner-occupied housing at the beginning of the risk period, which can vary across observations.
} 
Let $S(t)$ be the survival rate of remaining as a renter ${ }^{7}$ : the (conditional) density function for $t$ can be defined as $f\left(t \mid e_{i}=1\right)=h(t) S(t-1)$. The density function is defined conditional on $e_{i}=1$ and is irrelevant for households with $e_{i}=0$.

For the complete spell samples $\left(c_{i}=1\right)$, we can observe failure (i.e. housing purchases) at time $T_{i}$, and, of course, we know that they are prospective homeowners (i.e. $\left.e_{i}=1\right)$. The appropriate density is therefore given by $\operatorname{Pr}\left(e_{i}=1\right) h\left(T_{i}\right) S\left(T_{i}-\right.$ 1). On the other hand, for the incomplete spell samples, we can observe only $c_{i}=0$. There are two types of (renter) samples in this group that cannot be distinguished from each other. These are the following: (1) prospective homeowners who wish to purchase their own houses but still live in rental housing at $t=T_{i}$, and (2) perpetual renters who will never purchase a house. Therefore, the probability of $c_{i}=0$ is $\operatorname{Pr}\left(e_{i}=0\right)+\operatorname{Pr}\left(e_{i}=1\right) S\left(T_{i}\right)$, where the first component is the probability that household $i$ is a perpetual renter, and the second component is the probability that household $i$ is a prospective owner but do not purchase a house until $t=T_{i}$. Next, let $p_{i}$ denote the probability of never purchasing a house (i.e. $p_{i}=\operatorname{Pr}\left(e_{i}=0\right)$ ). The $\log$-likelihood function for observation $i$ is then given by ${ }^{8}$

$\ln L_{i}=c_{i}\left[\ln \left(1-p_{i}\right)+\ln \left(h\left(T_{i}\right)\right)+\ln \left(S\left(T_{i}-1\right)\right)\right]+\left(1-c_{i}\right) \ln \left(p_{i}+\left(1-p_{i}\right) S\left(T_{i}\right)\right)$

It can be easily observed that equation (3) includes the standard duration models as a special case, specifically when $p_{i}=0$, which implies that every household will eventually purchase a house. The duration models estimated in previous studies do not include the housing purchase decision (equation (1)) but focus only on the duration process. In the following analysis, we first exhibit the results from the standard model (i.e. the SPD model with $p_{i}=0$ ), and then present the estimation results from the SPD model, and subsequently, compare the estimates from both models.

\footnotetext{
${ }^{7}$ Note that $S(t)$ is the survival function conditional on being a potential owner. Obviously, $S(t)$ satisfies $S(t)=(1-h(t)) S(t-1)$, with $S(0)=1$ by definition.

${ }^{8}$ Estimation of the model is carried out using STATA, Version 9, with the author's own program, which is available on request.
} 
Finally, for the simulation analysis, the expected duration until a housing purchase within $\bar{T}$ years is calculated using the following conditional expectation calculation:

$$
E(T \mid T<\bar{T})=\left(\sum_{t=1}^{\bar{T}} t \cdot \hat{f}(t)\right) / \operatorname{Pr}(T<\bar{T}),
$$

where $\hat{f}(\cdot)$ is the estimated (conditional) density function for $t$ from the above model.

It is obvious that an increase in the likelihood of homeownership at each period (i.e. a larger hazard rate $\hat{h}(t)$ ) must be associated with a smaller probability of being a renter (i.e. a smaller survival rate $\hat{S}(t)$ ). Therefore, an earlier timing of a housing purchase can be demonstrated as being related to a higher hazard rate, a downward shift of the estimated survival curve $\hat{S}(t)$, or a shorter expected time until a housing purchase.

\section{Data and Variables}

\subsection{Data Description}

The data used in this analysis are taken from the Keio Household Panel Survey (KHPS) conducted by Keio University first in January 2004 and subsequently in 2005. This survey is supported by the Ministry of Education, Culture, Sports, Science and Technology and is the first comprehensive panel survey of households in Japan. The data include 4,005 male and female respondents between 20 and 69 years of age.

The KHPS provides information not only on the current state of the individuals but also on the history of each individual's characteristics starting from the age of 15 . The individual history includes retrospective information pertaining to the individuals' employment status and previous housing status. Using this information, we construct a (person-year) retrospective panel data set in order to examine the timing of the first-time home purchases of Japanese households. Apart from this retrospective information, the survey also reports various socio-economic attributes such as the age, education, income, and wealth of the respondents. 
Our retrospective panel data includes the following two types of households: (1) households owning their houses at the time of the survey (i.e. those who purchased their own houses at a certain time in the past: referred to as the owner sample) and (2) households living in rental housing at the time of the survey (referred to as the renter sample). The spell duration for the owner sample is defined as the husband's age at the time of purchase minus his age at the time of completion of his full-time education. For the renter sample, the spell duration is defined as the husband's current age minus his age at the time of completion of his full-time education. As a result, the owner sample includes the period from the time of graduation from school (the beginning of the spell duration) to the time of home purchase (exit time), while the renter sample includes the period from the time of graduation to the year when the current survey was conducted (2005). Since we can only observe the current and previous housing tenure status, we limit our sample to households whose husbands were less than 40 years of age at the time of their home purchases (for the owner sample) or at the time of the survey (for the renter sample). This ensures that the owners are still living in their first house and that the renters are not previous homeowners.

As a result, the data contain a sample of prospective first-time buyers who are married couples. After eliminating samples with missing or inconsistent information, we have 5,993 usable observations including 452 households (owner sample: 307; renter sample: 145). Table 1 presents the definitions and summary statistics of the variables.

(Table 1 around here.)

\subsection{Variables}

\section{Dependent Event of Home Purchase}

The dependent event - the household's home purchase - is defined as a dummy variable that takes the value of one if a household purchases its own house, or zero if it continues to live in rental housing. A house to be purchased can be either a 
detached house or a condominium. Houses acquired through inheritance from parents or other relatives are excluded from the event.

\section{Unemployment Risk}

As mentioned above, our data provide retrospective information on individual's employment history starting from the age of 15 , which allows us to identify whether or not a respondent was unemployed at each time $t$ in the past. Using this information, we estimate the probability that a male household head (husband) will become unemployed in the subsequent year, conditional on the current employment status, past unemployment history ${ }^{9}$, and a set of explanatory variables. This provides us with the transition probability of each individual becoming unemployed in the subsequent year (i.e. year $t+1$ ), depending on the current employment status (i.e. year $t) .{ }^{10}$ Due to this dependence, actual unemployment experience in a certain period increases the subsequent unemployment probability and, thus, sequentially affects the series of employment status. Since the model is effectively a Markov process, our measure of unemployment risk is given as $\operatorname{Pr}\left(U_{i, t+1} \mid U_{i t}\right)$, where $U_{i t}$ is defined, as before, as a binary indicator of unemployment, which takes the value of one if individual $i$ is unemployed in period $t$, and zero otherwise.

Recent empirical studies contend that there is reverse causality between unemployment and homeownership (Nickell 1998; Oswald 1999; Green and Henderschott 2001). Since homeowners are less mobile across geographic locations than are renters, homeownership itself affects labour market outcomes through location-specific shocks in the market. To cope with this endogeneity issue, we use the age-specific regional unemployment rate as an instrument for identification. ${ }^{11}$

\footnotetext{
${ }^{9}$ Literature in labour economics, for instance, Belzil (1995) and van den Berg and van Ours (1996), suggest that unemployment duration depends on previous unemployment experience.

${ }^{10} \mathrm{We}$ also estimated the models with a more detailed classification of current and future employment status, namely, unemployed, self-employed, and employed by a firm. However, they exhibit qualitatively same results as those in this paper.

${ }^{11}$ Carroll, Dynan, and Krane (2003) and Engen and Gruber (2001) also use regional variables as an instrument. They argue that regional variables are likely to satisfy the exogeneity requirement in the case of precautionary saving behaviour.
} 
The estimation results are presented in Table 2 .

(Table 2 around here.)

The results are intuitively plausible: Current unemployment is significantly associated with a higher probability of being unemployed in the subsequent year; a better educated individual is less likely to be unemployed; an individual with a father who was self-employed is also less likely to be unemployed; an individual who has experienced unemployment in the past is likely to be unemployed in the subsequent year; and the regional unemployment rate is strongly and positively related to the probability of unemployment.

Using this result, the predicted probability of being unemployed in period $t+1$ is calculated for each observation $i$ given the current employment status. In the following analysis, this estimated probability is used to measure the uncertainty of the husband's employment status and income.

\section{Accumulated Wealth}

As Jones (1995), Haurin, Hendershott, and Wachter (1995), and Moriizumi (2003) noted, a household's liquefiable wealth is endogenous to its housing purchase decision. To cope with this endogeneity problem, an instrumental variable (IV) approach has been commonly used in most of the previous empirical studies. In our data, there is no retrospective information on a household's liquefiable wealth; however, we have data on wealth from the 2004 survey year. Thus, we estimate a wealth equation using the relevant set of exogenous variables and use the predicted value of household wealth (WEALTH) in our model. Using a cross-section of the first wave, WEALTH is estimated by regressing the amount of total liquefiable assets (financial assets deflated by the CPI) on the husband's age and education and a set of household characteristics. Since a sizable portion of the households in our sample do not hold any liquefiable wealth, the wealth equation is estimated by a Tobit regression of the sample living in rental housing in 2004. The results of the Tobit 
estimation are as follows:

$$
\begin{aligned}
& \mathrm{WEALTH}=-660.82+12.959 \cdot \mathrm{AGE}+207.75 \cdot \mathrm{HIGH}+140.96 \cdot \mathrm{JCOL} \\
& \text { (294.61) (7.006) (164.75) (204.72) } \\
& +\underset{(167.00)}{527.94} \cdot \mathrm{COL}+\underset{(213.68)}{271.00} \cdot \mathrm{OTHER}-\underset{(81.946)}{88.321} \cdot \mathrm{EVERUE}+\underset{(0.063)}{0.121} \cdot P_{H},(5)
\end{aligned}
$$

where the standard errors are in parentheses. The definitions of the explanatory variables are as follows. AGE is the age of the husband. HIGH, JCOL, COL, and OTHER are dummy variables for the level of the husband's education, indicating that the respondent has graduated from high school, junior college, 4-year college or higher, and other educational institutes (such as vocational school etc.), respectively. Junior high school is omitted as a reference category. EVERUE is a dummy variable that takes the value of one if the husband has ever experienced unemployment. $P_{H}$ is the unit price of owner-occupied housing (prefecture-level), as discussed below.

\section{Macroindicators}

Besides the variables discussed above, additional data related to macroindicators, such as the unemployment rate, mortgage interest rate, and the relative price of owner-occupied housing, are used in our estimation. The mortgage interest rate (MR) is taken from the Financial and Economic Statistics Monthly (Bank of Japan). ${ }^{12}$ The relative price of owner-occupied housing (RELPRC) is defined as the unit price of owner-occupied housing $\left(P_{H}\right)$ divided by the regional housing rent index $\left(P_{R}\right)$. The unit price of owner-occupied housing, $P_{H}$, is calculated by the formula $P_{H}=$ $P_{K}^{\lambda} P_{L}^{1-\lambda}$, where $P_{K}$ is the construction cost per square metre of floor space, $P_{L}$ is the land price per square metre, and $\lambda$ is set at 0.5 . For $P_{K}$, the data on the construction cost of a structure per square metre of floor space are obtained from the Annual Survey of Statistics on Construction (Statistics Bureau, Ministry of Internal Affairs and Communications). For $P_{L}$, the data on the price per square metre of residential land are obtained from the Survey on Land Prices (MLIT). The data for both $P_{K}$ and $P_{L} \quad$ are collected at the prefecture-level. The regional index of housing rent $\left(P_{R}\right)$ is also a prefecture-level variable taken from the National Survey of Prices (Statistics

\footnotetext{
${ }^{12}$ In the analysis, we use the average mortgage interest rate of city banks deflated by the CPI.
} 
Bureau). Finally, an age-specific regional unemployment rate (UR, with a 5-year age interval) is taken from the Population Census of Japan (Statistics Bureau). To obtain this variable, the total number of unemployed individuals is divided by the total labour force of each population subgroup (i.e. unemployment rate is calculated for each 5-year age group in each prefecture).

\section{Empirical Results}

\subsection{Estimates of the Timing of Homeownership with the Discrete-Time Hazard Model}

The main results of the discrete-time hazard models are displayed in Table 3. The relationship between unemployment risk and homeownership is examined by the predicted probability of the husband's unemployment. Since the unemployment probability represents the unemployment risk faced by each household, it is expected that the unemployment probability has a negative impact on homeownership (i.e. the hazard rate). A lower hazard rate implies a delay in housing acquisition. In all the estimations, the baseline hazard is controlled by linear spline variables that are created by defining certain knots (5-year intervals in our specification) where the baseline hazard changes its slope. ${ }^{13}$

(Table 3 around here.)

First, we present the results from the discrete-time logit model (i.e. the SPD model with $p_{i}=0$ ), followed by the estimation results from the SPD model. Subsequently, we compare the estimates from both models.

The estimates of the discrete-time logit model are presented in the first column of Table 3. The following results are obtained. First, we find that a higher unemployment probability has a strongly negative impact on homeownership. It is

\footnotetext{
${ }^{13}$ Alternative parametric specifications of the baseline hazard (e.g. including dummies for each spell duration) or the semi-parametric Cox proportional hazard model do not change the result fundamentally. These are available upon request.
} 
demonstrated that, on average, a $10 \%$ increase in the unemployment probability decreases the annual probability of home purchase (i.e. the hazard rate) from $5.1 \%$ to $4.5 \%{ }^{14}$ The negative relationship exhibited in our estimation is consistent with the results of previous empirical studies such as Haurin (1991), Robst, Deitz, and McGoldrick (1999), and Diaz-Serrano (2005a), which use income volatility as a measure of income uncertainty.

With regard to the other variables, the following results are obtained: Wealthier households have a higher probability of homeownership, as expected; housing market characteristics such as the relative housing price and mortgage interest rate have significant effects on homeownership with the expected signs, i.e. relatively expensive owner-occupied housing and a higher mortgage interest rate discourage households from purchasing a house; and marriage and a larger number of children promote housing purchases. $^{15}$

The results from the SPD model are displayed in the second column of Table 3. The model consists of two equations: the duration equation, which represents the duration process applied to those who eventually purchase houses, and the splitting equation, which determines the decision to purchase a house.

The estimates of the SPD duration equation present results similar to those from the discrete-time logit model, except with regard to the effects of the unemployment probability and the baseline hazard. Although the unemployment probability is still significantly and negatively related to the probability of future homeownership, its magnitude is smaller in the SPD model than in the discrete-time logit model, where the sample of those who never purchase a house is not taken into consideration. This should be interpreted as a result of the misspecification of the baseline logit model,

\footnotetext{
${ }^{14}$ The baseline hazard of homeownership (5.1\%) is calculated in the following way. First, we calculate the estimated hazard for each individual based on the observed unemployment probability. We then average this estimated hazard of each individual to obtain the baseline value. The estimated hazard based on the unemployment probability increased by $10 \%$ from the observed value $(4.5 \%)$ is obtained in a similar manner.

${ }^{15}$ Since we cannot observe the past income stream from the data, we are forced to omit the measured income variable from our estimation. However, as Jones (1995) pointed out, accumulated wealth, rather than the permanent income level, is the major determinant of the housing acquisition decision.
} 
namely, the application of the duration process to those who would not eventually purchase a house. It is consistent with the notion that households with an extremely high probability of unemployment are less likely to purchase their own homes (i.e. they have zero probability of homeownership). Imposing a non-zero duration process on these households leads to an overestimation of the effect of unemployment risk. Also, the baseline hazard of home purchase is shown to be shifted upward in the SPD model, which is consistent with the above explanation. Since some households are found to have zero probability of purchasing a home (i.e. perpetual renters) in the SPD model, the remaining portion of households have higher baseline hazards, as suggested in the above explanation.

With regard to the splitting equation, we test the hypothesis that $p_{i}=0$, i.e. the probability of being a perpetual renter is zero. If the null hypothesis cannot be rejected, it can be claimed that all households will eventually purchase houses and that the SPD model will be the same as the discrete-time logit model. Therefore, the test can be used as a model selection procedure. The Wald test result is presented at the bottom of Table 3, and the standard error is obtained by the delta method. As a result, the null hypothesis is rejected, which necessarily supports the SPD model against the standard logit model. ${ }^{16}$

The estimates of the splitting equation suggest that a household's characteristics at the early stages of a life cycle affect its subsequent homeownership. Initial wealth holdings significantly increase the probability of a household eventually purchasing its own home. An initial unemployment risk, which is our central interest, also has a significantly positive effect on the probability of never purchasing a home. The initial conditions of housing and labour markets are also important: a higher unemployment rate or relative price of owner-occupied housing in the initial period discourages households from purchasing homes in the subsequent years. As illustrated in Figure 1, the unemployment rate of a younger individual rises steadily during our sample

\footnotetext{
${ }^{16}$ Since by definition, $p_{i} \geq 0$, testing $H_{0}: p_{i}=0$ (which is at the boundary of the parameter space) through the Wald test may be inappropriate. Therefore, the corresponding likelihood ratio test is also conducted, but it does not reveal any significant difference in the result.
} 
period. This coincides with the recent decline of homeownership rates among younger households in Japan.

In order to examine the impact of unemployment risk on the timing of homeownership, we conduct a simple simulation exercise based on the above results in the next section.

\subsection{Simulation Results}

In this subsection, we investigate the effect of unemployment risk on the timing of housing purchases by conducting a simulation exercise based on the SPD model presented in the previous section, and by examining the estimated homeownership probability $^{17}$ and the expected duration until a housing purchase. In this exercise, we examine the effect of initial unemployment (at the beginning of the spell) on homeownership. Throughout our simulation, we focus on the typical young renter with the following attributes: born in 1965 (i.e. 40 years of age in 2005), graduated from four-year college (i.e. spell duration starts at AGE $=22$ ), marries at the age of $24(\mathrm{MARR}=1$ if $\mathrm{AGE} \geq 24)$, has his first child at the age of 26 and the next child at the age of 30 (NUMCHILD $=1$ if $26 \leq \mathrm{AGE} \leq 29$ and NUMCHILD $=2$ if AGE $\geq 30$ ), has a father who is employed (FEMP $=1)$, and lives in the Tokyo metropolitan area. With regard to the macro variables, the following are applied: mortgage interest rate (MR) and relative price of owner-occupied housing (RELPRC) are assumed to be time invariant and are set as the sample averages (MR $=3.40$ and RELPRC $=15.12),{ }^{18}$ and the unemployment rate $(U R)$ is set at the age-specific average of prefectures in the Tokyo metropolitan area.

\footnotetext{
${ }^{17}$ Obviously, homeownership probability is defined as $1-S(t)$. Since the probability of never purchasing a house is not zero (approximately $1.6 \%$ for the representative individual's case), the definition of the survival rate is slightly different from that in equation (4). The definition of unconditional survival rate is given by

where $\hat{S}(0)=1$ by definition.

$$
\hat{S}(t)=p_{i}+\left(1-p_{i}\right)(1-\hat{h}(t)) \hat{S}(t-1),
$$

${ }^{18}$ The actual values of these two variables can be used in our simulation instead of the sample averages. However, because we focus on the effect of an unemployment experience, while holding other effects constant, we choose to use the time-invariant sample averages.
} 
By applying the above setting to our estimation results, we examine the effect of an actual unemployment experience at the beginning of the spell (i.e. unemployment at the age of 22) on subsequent homeownership. As a result of the intertemporal dependence on unemployment status, as discussed in Section 3, the experience of unemployment at the beginning of the spell increases the subsequent unemployment risk (i.e. the unemployment probability). The calculation of the sequence of unemployment probabilities is discussed in the Appendix. Since an initial state of unemployment increases the likelihood of being unemployed in the subsequent periods, the homeownership probability will be lower due to the increased unemployment risk.

It is found that the expected duration until a housing purchase-the conditional expected time until a home is purchased as given by equation (4) - is 14.9 years (Case 1: employed at the age of 22) and 16.5 years (Case 2: unemployed at the age of 22). ${ }^{19}$ It is clear from the result that a husband's unemployment experience in his younger years results in an increased unemployment risk and in insufficient wealth accumulation, thus postponing a home purchase. A one-year unemployment spell delays the timing of homeownership by nearly 1.6 years.

(Figure 2 around here.)

Figure 2 displays the estimated homeownership probability at each time point. It is exhibited that the estimated homeownership curve is shifted downward for Case 2 during the period following the unemployment experience (Spell $\geq 2$ ), resulting in a longer duration until a home purchase. As a result, the homeownership probability at $t=19$ will be approximately 0.72 in Case 1 , while it will be 0.59 in Case 2 .

\section{Conclusion}

In this paper, we examine the effects of unemployment risk on the timing of

\footnotetext{
${ }^{19}$ When calculating the conditional expected duration, we set $\bar{T}=39$ (i.e. the expected duration
} for those who purchase their homes prior to the age of 60). 
homeownership by using a retrospective panel of Japanese households. Our data, obtained from the KHPS, have several advantages over those used in previous works. First, the fairly long panel of individual households obtained from the survey's retrospective information enables us to analyse the long-run consequences of unemployment on the behaviour of first-time homeownership. Second, the KHPS provides rich information not only on the housing characteristics of a household including its history of housing tenure status but also on the history of its employment status and previous job changes. This facilitates the analysis of the impact of unemployment risk on the timing of homeownership. We estimate the unemployment risk using a retrospective panel data set of the KHPS to obtain a more precise measure than did previous studies.

Taking account of the fact that some portions of the population in the housing market will choose to never own a house, a factor which previous studies fail to introduce, the timing of first-time homeownership is analysed using the SPD model. We obtain the following conclusions: (1) unemployment risk, as proxied by the unemployment probability, has a significantly negative effect on homeownership and delays its timing, (2) the effect of unemployment risk is overestimated in previous studies which assume that all households will eventually become homeowners, and (3) household characteristics as well as the conditions of housing and labour markets at the early stages of a household's life cycle significantly affect the initial housing purchase decision. Finally, our simulation results indicate that an initial one-year unemployment spell will have a fairly large impact of a 1.6-year delay in the timing of a subsequent home purchase.

\section{Appendix}

\section{Sequence of Unemployment Probabilities}

The sequence of unemployment probabilities is calculated as follows. Let $U_{t}$ be the binary indicator of the actual unemployment in period $t$ (taking the value of one if unemployed and zero otherwise). Further, let $\operatorname{Pr}\left(U_{t+1}=1 \mid U_{t}\right)$ be the 
unemployment probability in $t+1$ conditional on $U_{t}$, which can be obtained from the estimation result in Table 1. Given an employment status in the first year (i.e. $t=1$ ), we consider two cases in our simulation analysis: (1) the baseline case in which $U_{1}=0$, and (2) the unemployed case in which $U_{1}=1$. Obviously, the unemployment probability in year 2 is

$$
\begin{aligned}
& \operatorname{Pr}\left(U_{2}=1 \mid U_{1}=0\right) \text { for baseline case and } \\
& \operatorname{Pr}\left(U_{2}=1 \mid U_{1}=1\right) \text { for unemployed case. }
\end{aligned}
$$

Using equation (6) as a starting point, we calculate the expected unemployment probability for each subsequent period by taking the occurrence of actual unemployment into consideration.

The expected unemployment probability in year 3 is

$$
\operatorname{Pr}\left(U_{3}=1 \mid U_{2}=0\right) \times \operatorname{Pr}\left(U_{2}=0 \mid U_{1}\right)+\operatorname{Pr}\left(U_{3}=1 \mid U_{2}=1\right) \times \operatorname{Pr}\left(U_{2}=1 \mid U_{1}\right),
$$

where $\operatorname{Pr}\left(U_{2}=0 \mid U_{1}\right)=1-\operatorname{Pr}\left(U_{2}=1 \mid U_{1}\right)$ by definition, and $\operatorname{Pr}\left(\mathrm{U}_{2}=1 \mid \mathrm{U}_{1}\right)$ is defined as equation (6). In equation (7), the first term indicates the unemployment probability in year 3 conditional on $U_{2}=0$, and the second term indicates the unemployment probability in year 3 conditional on $U_{2}=1$. In general, the expected unemployment probability in period $\tau>3$ is

$$
\operatorname{Pr}\left(U_{\tau}=1 \mid U_{\tau-1}=0\right) \times \operatorname{Pr}\left(U_{\tau-1}=0\right)+\operatorname{Pr}\left(U_{\tau}=1 \mid U_{\tau-1}=1\right) \times \operatorname{Pr}\left(U_{\tau-1}=1\right),
$$

where

$$
\begin{gathered}
\operatorname{Pr}\left(U_{\tau-1}=0\right)=1-\operatorname{Pr}\left(U_{\tau-1}=1\right), \text { and } \\
\operatorname{Pr}\left(U_{\tau-1}=1\right)=\operatorname{Pr}\left(U_{\tau-1}=1 \mid U_{\tau-2}=0\right)+\operatorname{Pr}\left(U_{\tau-1}=1 \mid U_{\tau-2}=1\right) .
\end{gathered}
$$

Using the above formula, we iteratively calculate the sequence of unemployment probabilities in our simulation exercises.

\section{Acknowledgements}

The authors are grateful to the $21^{\text {st }}$ Century Center Of Excellence program at Keio University for generously providing us with the Keio Household Panel Survey (KHPS). The authors would like to thank Edwin Deutsch, Viggo Nordvik, Piyush Tiwari, Miki Seko, Yoshio Higuchi, Colin McKenzie, Masayuki Nakagawa, and the 
participants of the 2006 Fall Meeting of the Japanese Economic Association and the European Network for Housing Research (ENHR) housing economics workshop in Copenhagen for their helpful comments and suggestions. The second author (Michio Naoi) acknowledges the receipt of a Grant-in-Aid (\#19730183) for Young Scientists from the Ministry of Education, Culture, Sports, Science and Technology.

\section{References}

Andrew, M., D. Haurin, and A. Munasib (2006) Explaining the route to owner-occupation: a transatlantic comparison, Journal of Housing Economics, 15, 189-216.

Belzil, C. (1995) Unemployment insurance and unemployment over time: an analysis with event history data, Review of Economics and Statistics, 77, 113-26.

Bound, J., and A. B. Krueger (1991) The extent of measurement error in longitudinal earnings data: do two wrongs make a right?, Journal of Labor Economics, 9, 1-24.

Carroll, C. D., K. E. Dynan, and S. D. Krane (2003) Unemployment risk and precautionary wealth: evidence from households' balance sheets, Review of Economics and Statistics, 85, 586-604.

DeSalvo, J. S., and L. R. Eeckhoudt (1982) Household behavior under income uncertainty in a monocentric urban area, Journal of Urban Economics, 11, 98-111.

Deutsch, E., P. Tiwari, and Y. Moriizumi (2006) The slowdown in the timing of housing purchases in Japan in the 1990s, Journal of Housing Economics, 15, 230-56.

DeYoung, R. (2003) The failure of new entrants in commercial banking markets: a split-population duration analysis, Review of Financial Economics, 12, 7-33.

Di Salvo, P., and J. Ermisch (1997) Analysis of the dynamics of housing tenure choice in Britain, Journal of Urban Economics, 42, 1-17.

Diaz-Serrano, L. (2005a) Labor income uncertainty, skewness and homeownership: a panel data study for Germany and Spain, Journal of Urban Economics, 58, 
156-76.

Diaz-Serrano, L. (2005b) On the negative relationship between labor income uncertainty and homeownership: risk-aversion vs. credit constraints, Journal of Housing Economics, 14, 109-26.

Engen, E. M., and J. Gruber (2001) Unemployment insurance and precautionary saving, Journal of Monetary Economics, 47, 545-79.

Forster, M., and A. M. Jones (2001) The role of tobacco taxes in starting and quitting smoking: duration analysis of British data, Journal of Royal Statistical Society A, 167, 517-47.

Fu, Y. (1995) Uncertainty, liquidity, and housing choices, Regional Science and Urban Economics, 25, 223-36.

Green, R., and P. Henderschott (2001) Home-ownership and unemployment in the US, Urban Studies, 38, 1509-20.

Guiso, L., and T. Jappelli (2002) Private transfers, borrowing constraints and the timing of homeownership, Journal of Money, Credit, and Banking, 34, 315-39.

Guiso, L., T. Jappelli, and D. Terlizzese (1992) Earnings uncertainty and precautionary saving, Journal of Monetary Economics, 30, 307-37.

Haurin, D., P. Hendershott, and S. Wachter (1995) Wealth accumulation and housing choices of young households: an explanatory investigation, NBER working paper, No.5070.

Haurin, D. R. (1991) Income variability, homeownership, and housing demand, Journal of Housing Economics, 1, 60-74.

Haurin, D. R., and H. L. Gill (1987) Effects of income variability on the demand for owner-occupied housing, Journal of Urban Economics, 22, 136-50.

Jones, L. D. (1995) Testing the central prediction of housing tenure transition models, Journal of Urban Economics, 38, 50-73.

Kidd, M. P., and S. Hopkins (2004) The hazards of starting and quitting smoking: some Australian evidence, Economic Record, 80, 177-92.

Lusardi, A. (1997) Precautionary saving and subjective earnings variance, Economics Letters, 57, 319-26. 
Lusardi, A. (1998) On the importance of the precautionary saving motive, American Economic Review, 88, 449-53.

Moriizumi, Y. (2003) Targeted saving by renters for housing purchase in Japan, Journal of Urban Economics, 53, 494-509.

Naoi, M., and Y. Moriizumi (2007) Housing tenure transition and female labor supply in Japan, mimeo.

Nickell, S. (1998) Unemployment: questions and some answers, Economic Journal, 108, 802-16.

Oswald, A. J. (1999) The housing market and Europe's unemployment: a non-technical paper, mimeo.

Robst, J., R. Deitz, and K. McGoldrick (1999) Income variability, uncertainty and housing tenure choice, Regional Science and Urban Economics, 29, 219-29.

Schmidt, P., and A. D. Witte (1989) Predicting criminal recidivism using 'split population' survival time models, Journal of Econometrics, 40, 141-59.

Tiwari, P., E. Deutsch, and Y. Moriizumi (2007) Housing finance arrangements, wealth positioning and housing consumption in Japan: an analysis of built-for-sale homeowners, Journal of Real Estate Finance and Economics, 34, 347-67.

Turnbull, G. K., J. L. Glascock, and C. F. Sirmans (1991) Uncertain income and housing price and location choice, Journal of Regional Science, 31, 417-33.

van den Berg, G. J., and J. C. van Ours (1996) Unemployment dynamics and duration dependence, Journal of Labor Economics, 14, 100-25.

Yamaguchi, K. (1991) Event History Analysis, Sage Publications, Newbury Park, CA. 
Table 1: Definitions and Descriptive Statistics

\begin{tabular}{|c|c|c|c|c|}
\hline Variables & Mean & (SD) & Min & Max \\
\hline \multicolumn{5}{|l|}{ Baseline Hazard } \\
\hline Length of spell (in years) & 7.921 & $(4.948)$ & 1 & 23 \\
\hline \multicolumn{5}{|l|}{ Demographic Characteristics } \\
\hline Age & 27.294 & $(5.147)$ & 18 & 40 \\
\hline Year of birth & 1965.726 & $(6.020)$ & 1952 & 1985 \\
\hline Married ( 1 = yes $)$ & 0.551 & $(0.497)$ & 0 & 1 \\
\hline Number of children & 0.589 & $(0.861)$ & 0 & 5 \\
\hline Years of education & 13.554 & $(2.117)$ & 9 & 18 \\
\hline \multicolumn{5}{|l|}{ Household Characteristics } \\
\hline Household wealth (predicted) & 247.655 & $(241.487)$ & 0 & 1099 \\
\hline \multicolumn{5}{|l|}{ Job-related Characteristics } \\
\hline Unemployed in the current year $(1=$ yes $)$ & 0.062 & $(0.241)$ & 0 & 1 \\
\hline Ever been unemployed ( 1 = yes $)$ & 0.297 & $(0.457)$ & 0 & 1 \\
\hline \multicolumn{5}{|l|}{ Family Background } \\
\hline \multicolumn{5}{|c|}{ Father's employment status (when the respondent was 15 years old) } \\
\hline Self-employed & 0.281 & $(0.450)$ & 0 & 1 \\
\hline Employed (temporary/regular) & 0.542 & $(0.498)$ & 0 & 1 \\
\hline \multicolumn{5}{|l|}{ Labor Market Characteristics } \\
\hline Age-specific regional unemployment rate & 4.606 & $(2.572)$ & 1.3 & 31.4 \\
\hline \multicolumn{5}{|l|}{ Housing Market Characteristics } \\
\hline Relative price of owner-occupied housing & 15.122 & $(4.999)$ & 2.332 & 28.646 \\
\hline Mortgage interest rate & 3.399 & $(1.649)$ & -13.752 & 6.374 \\
\hline Number of observations & \multicolumn{4}{|c|}{5993} \\
\hline Number of households & \multicolumn{4}{|c|}{452} \\
\hline Number of homeowners & \multicolumn{4}{|c|}{307} \\
\hline
\end{tabular}


Table 2: Logit Estimates of Unemployment Probability

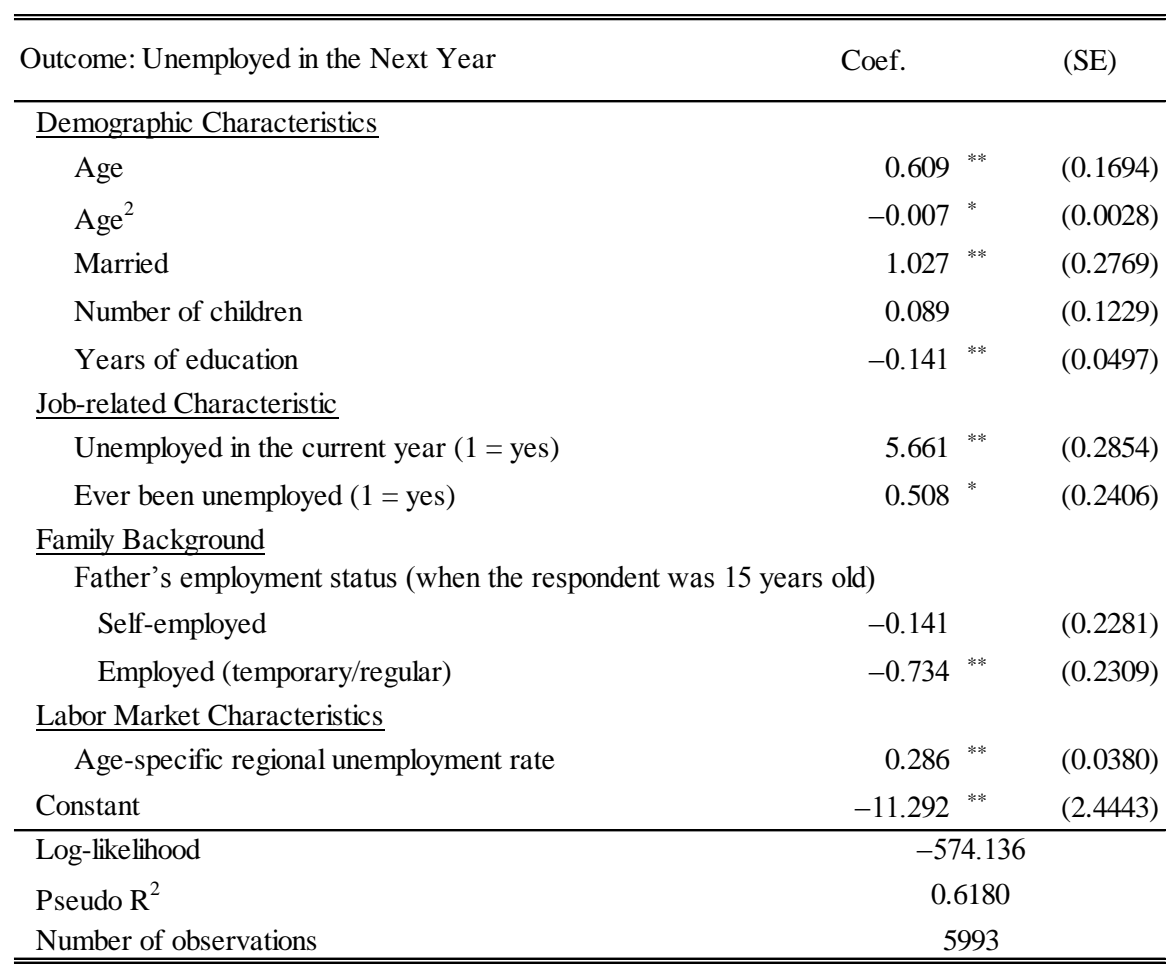

Note: A set of dummy variables for calendar time (with a 5-year interval) and regions are also included to control for time and region-specific effects. ** and * indicate that the estimated coefficient is significant at the 0.01 and 0.05 levels, respectively. Robust standard errors are presented in parentheses. 
Table 3: Discrete-Time Hazard Estimates of First-time Homeownership

\begin{tabular}{|c|c|c|c|c|c|}
\hline & \multicolumn{2}{|c|}{$\begin{array}{l}\text { SPD Model } \\
\text { with } p_{i}=0\end{array}$} & \multicolumn{3}{|c|}{$\begin{array}{c}\text { SPD } \\
\text { Model }\end{array}$} \\
\hline & Coef. & (SE) & Coef. & & (SE) \\
\hline \multicolumn{6}{|l|}{ Duration Equation: } \\
\hline \multicolumn{6}{|l|}{ Baseline Hazard (length of spell, spline variable) } \\
\hline 1 to 5 years & $0.249^{*}$ & $(0.1214)$ & 0.272 & * & $(0.1221)$ \\
\hline 6 to 10 years & $0.213^{* *}$ & $(0.0552)$ & 0.223 & $* *$ & $(0.0557)$ \\
\hline 11 to 15 years & $0.202^{* *}$ & $(0.0366)$ & 0.210 & $* *$ & $(0.0370)$ \\
\hline 16 to 20 years & $0.178^{* *}$ & $(0.0284)$ & 0.190 & $* *$ & $(0.0291)$ \\
\hline 21 years and above & $0.178^{* *}$ & $(0.0277)$ & 0.218 & $* *$ & $(0.0323)$ \\
\hline \multicolumn{6}{|l|}{$\underline{\text { Demographic Characteristics }}$} \\
\hline Married & $2.049^{* *}$ & $(0.3618)$ & 2.029 & $* *$ & $(0.3600)$ \\
\hline Number of children & $0.294^{* *}$ & $(0.0724)$ & 0.294 & $* *$ & $(0.0751)$ \\
\hline \multicolumn{6}{|l|}{$\underline{\text { Household Characteristics }}$} \\
\hline Household wealth (predicted) & $0.002^{* *}$ & $(0.0003)$ & 0.002 & ** & $(0.0004)$ \\
\hline \multicolumn{6}{|l|}{ Unemployment Risk } \\
\hline $\operatorname{Pr}($ Unemployed in the next year) & $-1.619^{* *}$ & $(0.4356)$ & -1.534 & $* *$ & $(0.4466)$ \\
\hline \multicolumn{6}{|l|}{ Housing Market Characteristics } \\
\hline Relative price of owner-occupied housing & $-0.056^{* *}$ & $(0.0192)$ & -0.058 & ** & $(0.0195)$ \\
\hline Mortgage interest rate & $-0.251^{* *}$ & $(0.0447)$ & -0.243 & $* *$ & $(0.0458)$ \\
\hline Constant & $-5.744^{* *}$ & $(0.5605)$ & -5.937 & $* *$ & $(0.5718)$ \\
\hline \multicolumn{6}{|l|}{ Splitting Equation: } \\
\hline \multicolumn{6}{|l|}{$\underline{\text { Household Characteristics }}$} \\
\hline Household wealth (predicted) & & & 0.042 & * & $(0.0199)$ \\
\hline \multicolumn{6}{|l|}{ Unemployment Risk } \\
\hline $\operatorname{Pr}($ Unemployed in the next year) & & & -4.669 & * & $(2.0862)$ \\
\hline \multicolumn{6}{|l|}{$\underline{\text { Housing Market Characteristics }}$} \\
\hline Relative price of owner-occupied housing & & & -0.388 & + & $(0.2218)$ \\
\hline Mortgage interest rate & & & -0.591 & & $(0.7115)$ \\
\hline \multicolumn{6}{|l|}{ Labor Market Characteristics } \\
\hline Unemployment rate & & & -5.677 & + & $(2.9890)$ \\
\hline Constant & & & 35.533 & & $(23.5069)$ \\
\hline $\operatorname{Pr}($ never purchase a house) & 0.000 & (restricted) & 0.016 & ** & $(0.0025)$ \\
\hline Log-likelihood & \multicolumn{2}{|c|}{-942.750} & \multicolumn{3}{|c|}{-928.345} \\
\hline Number of observations & \multicolumn{2}{|c|}{5993} & \multicolumn{3}{|c|}{5993} \\
\hline
\end{tabular}

Note: A set of dummy variables for the birth cohort (with a 10-year interval) and regions is also included to control for cohort and region-specific effects. ${ }^{*}, *$, and + indicate that the estimated coefficient is significant at the $0.01,0.05$, and 0.10 levels, respectively. Robust standard errors are in parentheses for the SPD model (with $p_{i}=0$ ). Explanatory variables used in the splitting equation are fixed at their initial (i.e., beginning of the spell) values. 


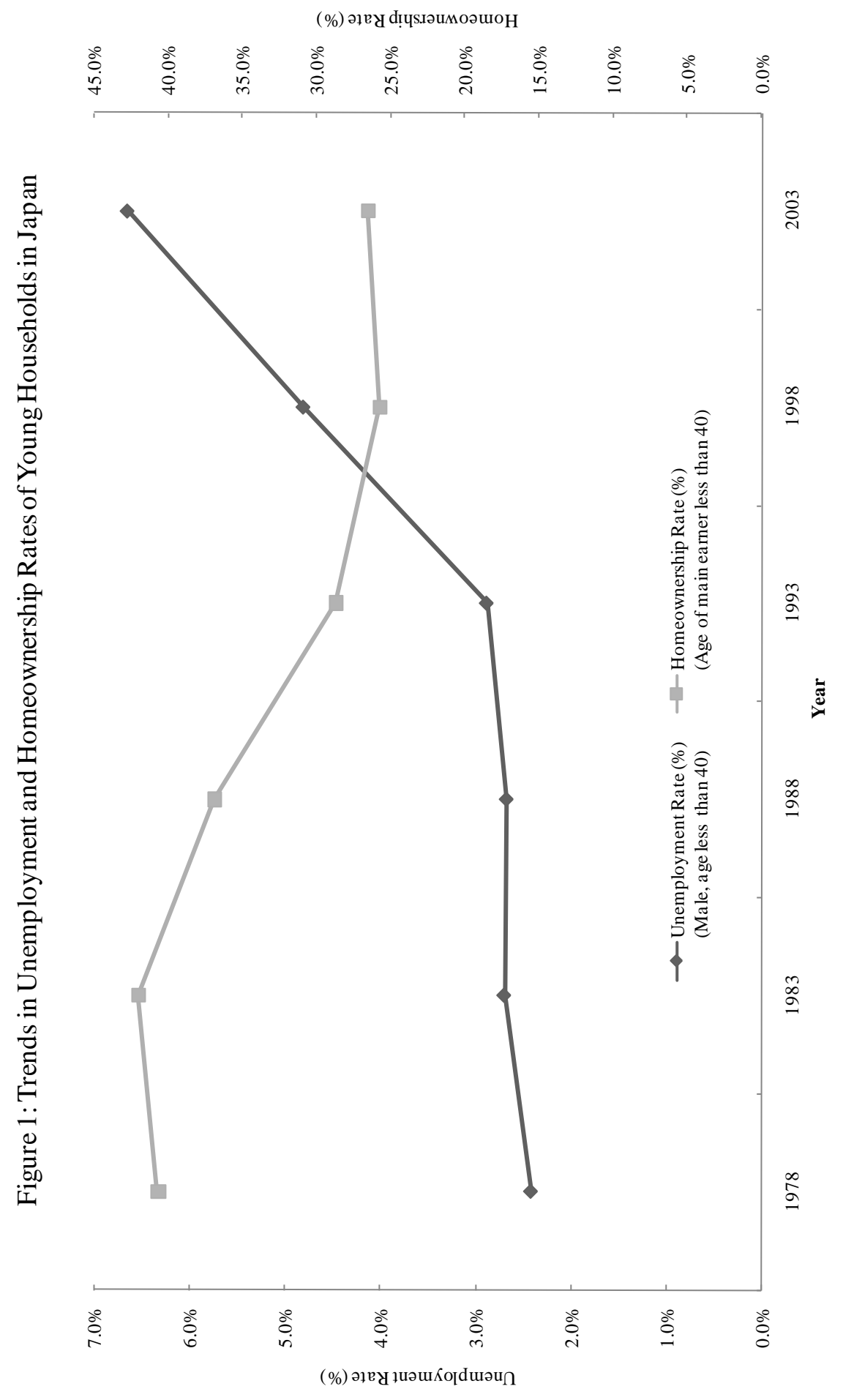




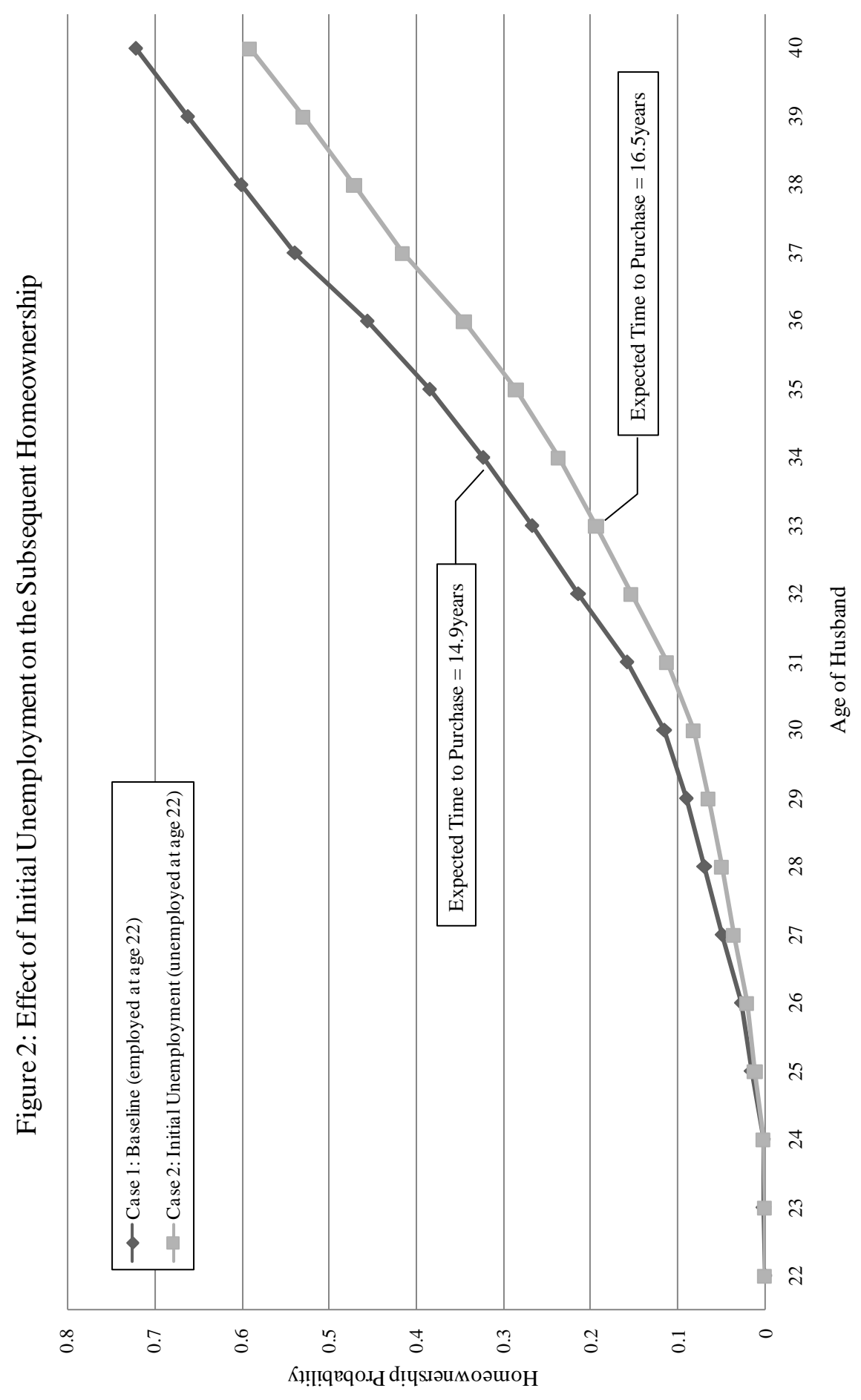

